\title{
Research Paper: Comparison of the Plantar Pressure and Foot Function and Range of Motion in Distance Runners With the Normal, Pronated, and Supinated Feet During Static Standing
}

\author{
Navid Keivanfar $^{1}$ (D), Azadeh Shadmehr ${ }^{1 *}$ (D) Khadijeh Otadi $^{1}$ (D), Seyed Mohsen Mir ${ }^{1}$ (D, Saman Salehi' ${ }^{1}$ (D)
}

1. Department of Physiotherapy, School of Rehabilitation, Tehran University of Medical Sciences, Tehran, Iran.

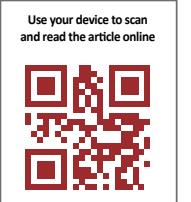

eftat One Keivanfar N, Shadmehr A, Otadi K, Mir SM, Salehi S. Comparison of the Plantar Pressure and Foot Function and Range of Motion in Distance Runners With the Normal, Pronated, and Supinated Feet During Static Standing. Journal of Modern Rehabilitation. 2020; 15(1):15-24. http://dx.doi.org/10.32598/JMR.15.1.3

http://dx.doi.org/10.32598/JMR.15.1.3

Article info:

Received: 10 Aug 2020

Accepted: 20 Sep 2020

Available Online: 01 Jan 202
Keywords:

Foot function index, Foot posture, Plantar pressure, Plantar contact are, Foot function, Range of motion

\section{ABSTRACT}

Introduction: This study aimed to investigate the foot function, range of motion, plantar pressure, and plantar contact area in the distance runners with normal, pronated, highlypronated, supinated, and highly-supinated foot posture groups during static standing.

Materials and Methods: In this comparative cross-sectional study, a total of 75 distance runners were divided into 5 groups using the foot posture index. The foot function and knee and foot range of motion were assessed using the Foot And Ankle Ability Measure questionnaire (FAAM) and the goniometer, respectively. The mean of the plantar pressure percentage and the mean of the contact area on the forefoot and rearfoot were investigated during static standing. One-way ANOVA was used to compare the outcomes between the groups.

Results: Among the groups, the normal foot group showed the highest scores in the activities of daily living subscale and sport subscale. Compared with the other groups, the highly-pronated foot group had a significantly greater range of motion in the ankle plantar flexion $(\mathrm{P}<0.002)$, and the normal foot group showed more range of motion in the first metatarsophalangeal extension $(\mathrm{P}<0.0001)$. In all groups, the mean plantar pressure percentage on the rearfoot was greater than the mean plantar pressure percentage on the forefoot. Of the groups, the highly-supinated foot group showed the highest plantar pressure percentage on the rearfoot $(\mathrm{P}<0.0001)$. However, the highly-pronated foot group showed the highest plantar pressure percentage and the largest contact area on the forefoot $(\mathrm{P}<0.0001)$ and the rearfoot $(\mathrm{P}>0.0001)$, respectively.

Conclusion: Based on the results of this study, the foot posture is an important option that could affect function and range of motion of foot and ankle and distribution of the plantar pressure and plantar contact area. 


\section{Introduction}

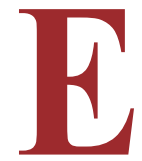

vidence suggests that injuries of the lower limb in athletes can be influenced by intrinsic and extrinsic risk factors $[1,2]$. The studies have found significant relationships between foot posture as an intrinsic risk factor and lower extremity injury [3-6]. The studies have shown that pes planus foot (low medial longitudinal arch) is associated with soft tissue injuries of lower limb $[7,8]$, including plantar fasciitis, patellofemoral pain syndrome, Achilles tendonitis, and knee pain in the athletes. Also, pes cavus foot is associated with injury to bony structures on the lateral aspect of the lower extremity such as medial tibia stress fracture and fifth metatarsal stress fracture [8].

Numerous studies have compared the kinetics and kinematic of the foot between various foot postures [6, 9-15]. The kinematic studies have presented that individuals with pes planus have greater foot mobility than individuals with cavus feet $[6,9,10,16]$. A systematic review has shown that subjects with pes planus feet exhibit more rearfoot inversion and adduction than subjects with normal feet posture [17].

Besides, several studies using foot scans have shown a set of evidence that supports a link between changes in foot posture and plantar pressure distribution [2, 18-21]. A systematic review has found that, during walking in the adult, planus feet compared to pes cavus and normal feet have higher pressure in the medial arch, central forefoot, and hallux and have lower pressure in the lateral and medial forefoot [22]. In contrast, compared with normal feet and pes planus feet, subjects with pes cavus feet have shown higher pressure in the heel and lateral forefoot and lower pressure in the hindfoot and hallux [22].

Although there are indications that plantar pressure distribution and range of motion of lower limb can be influenced by foot posture, the previous studies that evaluated plantar pressure distribution and kinematic of lower limb extremity in subjects with various foot postures were not entirely consistent $[17,22]$ and the results of these studies were inconsistent due to variations in foot posture classification and evaluation of the range of motion.

For example, a few studies compared all foot postures, including normal, pes cavus, and pes planus feet [13, 21]. Additionally, different studies have used different segmental models to classify foot postures [3, 21, 2326]. Also, several studies used foot posture classification methods that are not regarded as the gold standard [27,
28]. One of the common methods for categorizing foot posture is the Foot Posture Index (FPI).

The FPI is a valid and reliable clinical assessment tool used to classify foot posture [29]. Morrison et al. investigated the inter-rater reliability of the FPI on pediatric subjects [30]. The average kappa score for inter-rater reliability was 0.88 [30]. Aquino et al. assessed the reliability of the FPI on adults and older adults [31]. An average Intra-Class Correlation (ICC) coefficient for interrater reliability was 0.79 for adults and 0.69 for older adults [31]. Besides, according to FPI, 5 foot groups were considered for this study.

In addition, studies have shown that foot postures have a known relationship with foot and lower limb function $[32,33]$. Accordingly, in the current study, the level of function of the foot and ankle of all participants was measured by the Foot And Ankle Ability Measure (FAAM) questionnaire. It is a valid and reliable self-administered measure, which assesses the level of function of the foot and ankle [34, 35].

So, the first aim of this study was to determine whether there is a difference in the functional ability of foot and ankle using FAAM (foot and ankle ability measure) questionnaire between 5 groups with different foot postures using FPI that is supported with normative data. Second, we aimed to assess whether foot and knee mobility is different between the 5 groups. The last aim was to compare plantar pressure and the plantar contact area between the groups.

\section{Materials and Methods}

In this comparative cross-sectional study, 75 distance runners (33 women, 42 male) aged between 20 to 30 years were included. The sample size was estimated, using G-power software (version 3.1.9.2) with a confidence level of $95 \%$ and power of $80 \%$, and the effect size was calculated using Andrew K. Buldt et al. study [21].

The runners were recruited via advertisements on social networks. All athletes in this study were middle-distance runners who usually run in races of 1 to $5 \mathrm{~km} 2$ times a week. The inclusion criteria were distance runners aged between 20 to 30 years, foot pain of lower than 3 according to visual analog scale, without a history of radicular low back pain, direct trauma during two last months, without neurological or cardiac disease, musculoskeletal disorder as tarsal tunnel syndrome, plantar fasciitis and history of fracture in the foot and ankle $[10,21]$. We excluded participants if they were not willing to perform the assessment. 
First, the FPI was used to classify foot postures. Foot postures in this study were determined using the FPI which is a valid and reliable index for identifying the foot posture [31]. The FPI is a 6-item scale of [26, 29] palpation of the head of the talus, curvatures above and below the lateral malleolus, position of the calcaneus in the frontal plane, prominence in the talonavicular joint, the medial longitudinal arch's congruence, and abduction/adduction of the forefoot on the rearfoot.

To determine foot posture using the FPI, the subjects were tested in a standing position. Each item of FPI was assessed by two physiotherapists. The score of each item of the FPI is from -2 to +2 and the total score of the FPI is between -12 to +12 . If there was any disagreement between two physiotherapists in item score; the third examiner was asked to identify the final score. According to the total score of the FPI, the distance runners were categorized into 5 groups. The normal feet group was characterized by the FPI score between 0 to 5 , while the pronated feet group and highly-pronated feet group were characterized by the FPI score between 6 to 9, respectively [26, 29].

The supinated feet group and highly supinated feet group were defined as having the FPI score between -6 to -9 and the FPI score between -9 to -12 , respectively $[26,29]$. Fifteen subjects were selected for each group. One foot of each runner was chosen for assessments. If only one foot of a runner had the parameters for a group, then this foot was selected. If both feet of a runner had the parameters for a group, the dominant foot was selected. To determine the dominant foot, the participants were asked to shoot a soccer ball on the target. Each one was used, it was considered the dominant foot.

Foot and ankle ability measure questionnaire (FAAM)

All participants filled out the questionnaire of Foot and Ankle Ability measure (FAAM) [35]. This questionnaire was reported to be reliable, and valid for evaluating ankle and foot performance in the Iranian population [34]. The FAAM has 29 items which comprise two subscales: activity of daily living (21 items) and sport ( 8 items). Each item ranged from 0 (no difficulty) to 4 (unable to do). The total score of the Activities of Daily Living (ADLs) subscale is 84 and the total score of the sport subscale is 32 [35]. The total score of each subscale is transformed into a percentage. Higher scores represent better performance in each subscale. Also, the FAAM has 3 overall scales.

In 2 overall scales, the subjects are asked to score their level of function during ADL and sports activities from
0 to 100 and on another scale, the subjects are asked to rate their current level of function. This item is scored on a 4-point Likert-type scale as normal, nearly normal, abnormal, and severely abnormal.

\section{Measurement of range of motion}

Active range of motions of knee extension, knee flexion, ankle dorsiflexion, ankle plantar flexion, and first Metatarsal Phalangeal (MTP1) extension was measured using the universal goniometer (a 360-degree circle, made in Iran) the same as that described by Norkin and White (2016) [36]. Each range of motion was measured 3 times and the mean values were used for statistical analysis.

\section{Plantar pressure and contact area}

Plantar pressure and contact area were recorded by a plantar pressure system (made in Belgium; $1 \mathrm{~m} \times 0.7 \mathrm{~m}$; sampling frequency $100 \mathrm{~Hz}$ ). All the participants were constructed to stand with bare feet on the foot scan with the feet approximately at pelvis width apart, to look straight forward to the target on the wall, to hold their arms along the body in a free position, to distribute equal weight on their feet. They were asked to stand $30 \mathrm{sec}-$ onds on the platform [37]. This trial was repeated two times and the mean values were used for statistical analysis. In this study, the foot was divided into two parts.

One part was named the rearfoot that included medial heel, lateral heel, and midfoot, and the other part was named the forefoot that included the metatarsals and the

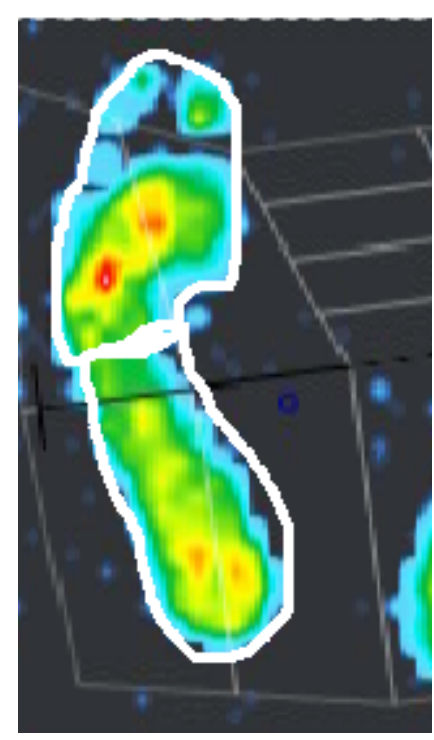

JMR

Figure 1. Foot divisions: the rear foot, including medial heel, lateral heel, and midfoot and the forefoot, including the metatarsals and the phalanges 


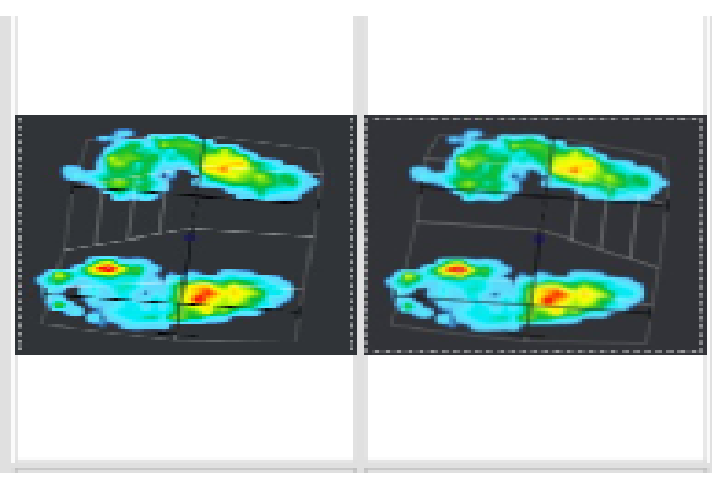

(B)

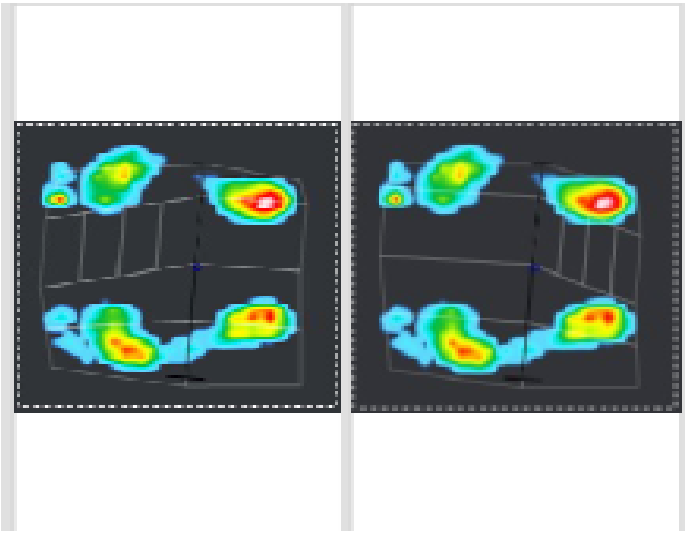

(A)

Figure 2. Plantar pressure diagrams for two foot postures based on the FPI

A: Highly-pronated foot; B: Highly-supinated foot, red indicates greater peak plantar pressure values and blue indicates lesser peak plantar pressure values

phalanges. The following data were extracted pressure percentage under the rearfoot, pressure percentage under the forefoot, the contact area of the forefoot $\left(\mathrm{cm}^{2}\right)$, the contact area of the rearfoot $\left(\mathrm{cm}^{2}\right)$ (Figure 1). Plantar pressure diagrams for the highly-supinated foot and highly-pronated foot are shown in Figure 2.

\section{Statistical analysis}

Statistical analyses in this study were performed in SPSS v. 20. All variables are presented as Mean \pm SD.
The variables were tested for normal distribution by the Kolmogorov-Smirnov test. All variables were normally distributed. One-way ANOVA was used to compare numeric variables between the distance runners with normal foot group, pronated foot group, highly-pronated foot group, supinated foot group, highly-supinated foot group. Each variable was analyzed independently. If there were significant differences between the groups, the Bonferroni post hoc test was performed. The Chi-square

Table 1. Demographic data of the participants $(n=15)$

\begin{tabular}{|c|c|c|c|c|c|c|}
\hline \multirow{2}{*}{ Variables } & \multicolumn{5}{|c|}{ Mean士SD/ No. (\%) } & \multirow{2}{*}{$\mathbf{P}$} \\
\hline & NG & PG & HPG & SG & HSG & \\
\hline Age (y) & $24.20 \pm 3.80$ & $25.60 \pm 3.20$ & $24.13 \pm 2.74$ & $24.66 \pm 2.79$ & $24.60 \pm 2.92$ & 0.71 \\
\hline Weight (kg) & $71.1 \pm 2.74$ & $72.20 \pm 3.46$ & $71.46 \pm 2.77$ & $72.46 \pm 4.05$ & $72.33 \pm 3.22$ & 0.75 \\
\hline Height (cm) & $179 \pm 3.83$ & $180.60 \pm 3.88$ & $180 \pm 3.74$ & $181.66 \pm 3.63$ & $182 \pm 3.27$ & 0.24 \\
\hline $\mathrm{BMI}\left(\mathrm{kg} / \mathrm{cm}^{2}\right)$ & $22.18 \pm 1.11$ & $22.15 \pm 1.92$ & $21.87 \pm 0.95$ & $22.51 \pm 1.24$ & $22.06 \pm 0.82$ & 0.60 \\
\hline Foot length $(\mathrm{cm})$ & $26.66 \pm 1.8$ & $25.93 \pm 2.54$ & $27 \pm 1.77$ & $26.93 \pm 1.79$ & $26.32 \pm 1.77$ & 0.54 \\
\hline Foot width $(\mathrm{cm})$ & $7.04 \pm 0.85$ & $7.29 \pm 0.53$ & $6.95 \pm 0.88$ & $7.11 \pm 0.80$ & $7.43 \pm 0.70$ & 0.43 \\
\hline \multirow[t]{2}{*}{ Female } & $5(33.3)$ & $7(46.7)$ & $7(47.7)$ & $6(40)$ & $8(53.3)$ & \multirow{3}{*}{0.84} \\
\hline & & & & & & \\
\hline Male & $10(66.7)$ & $8(53.3)$ & $8(53.3)$ & $9(60)$ & $7(46.7)$ & \\
\hline
\end{tabular}

IPT: Isometric Peak Torque; Nm: Newton Meter; CM: Centimeter; HPL: High Power Laser; SLHT: Single-Leg Hop; NG: Normal Foot Group; PG: Pronated Foot Group; HPG: Highly-Pronated Foot Group; SGA: Supinated Foot Group; HSG: HighlySupinated Foot Group 
Table 2. FAAM questionnaire results, including all group Mean $\pm S D, P$ value of 1-way ANOVA, F index, P value of Bonferroni post hoc test (group 1 vs. group 2$)^{*},(n=15)$

\begin{tabular}{|c|c|c|c|c|c|c|c|c|c|c|c|c|c|c|c|c|}
\hline \multirow{2}{*}{\multicolumn{2}{|c|}{$\begin{array}{c}\text { Groups } \\
\text { Variables }\end{array}$}} & \multicolumn{5}{|c|}{ Mean $\pm S D$} & \multicolumn{2}{|c|}{ df } & \multirow[b]{2}{*}{$\mathbf{P}$} & \multirow[b]{2}{*}{$\begin{array}{l}\text { F In- } \\
\text { dex }\end{array}$} & \multicolumn{3}{|c|}{ vs. HPG } & \multicolumn{3}{|c|}{ vs. HSG } \\
\hline & & NG & PG & HPG & SG & HSG & $\begin{array}{c}\text { Between } \\
\text { Groups }\end{array}$ & $\begin{array}{l}\text { Within } \\
\text { Groups }\end{array}$ & & & NG & SG & NG & PG & HPG & SG \\
\hline \multirow{2}{*}{$\frac{\overline{\frac{0}{0}}}{\frac{0}{\sqrt{0}}}$} & $\begin{array}{l}\frac{0}{\bar{n}} \\
\stackrel{5}{0} \\
\frac{0}{4}\end{array}$ & $\begin{array}{l}\text { ov } \\
\infty \\
+i \\
+1 \\
\infty \\
\infty \\
\infty \\
\infty\end{array}$ & $\begin{array}{l}\stackrel{N}{a} \\
\substack{+1 \\
+} \\
\stackrel{+}{a}\end{array}$ & $\begin{array}{l}\text { N } \\
\stackrel{+}{+} \\
+1 \\
\stackrel{1}{+} \\
\dot{J}\end{array}$ & $\begin{array}{l}0 \\
0 \\
+1 \\
+1 \\
\stackrel{1}{1} \\
\infty \\
0\end{array}$ & \begin{tabular}{l}
$\stackrel{+}{n}$ \\
\multirow{N}{N}{} \\
\multirow{N}{N}{} \\
\end{tabular} & $\sigma$ & $\pi$ & $\begin{array}{l}3 \\
3 \\
8 \\
0\end{array}$ & 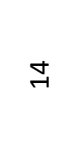 & 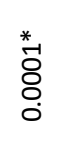 & $\stackrel{*}{\tilde{O}}$ & $\begin{array}{l}\stackrel{*}{\circ} \\
\stackrel{\circ}{0} \\
0\end{array}$ & $\begin{array}{l}\stackrel{*}{\circ} \\
\stackrel{\circ}{0} \\
0\end{array}$ & & 范 \\
\hline & $\begin{array}{l}\frac{0}{5} \\
\text { ज } \\
\text { t̀ } \\
\text { ñ }\end{array}$ & 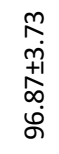 & $\begin{array}{l}n \\
0 \\
m \\
+1 \\
0 \\
0 \\
\dot{0}\end{array}$ & $\begin{array}{l}\stackrel{+}{\infty} \\
\text { + } \\
\text { 就 }\end{array}$ & 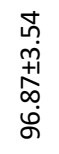 & 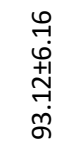 & $\nabla$ & $\stackrel{N}{N}$ & $\begin{array}{c}\text { m } \\
\stackrel{-}{0} \\
\text { - }\end{array}$ & $\sim$ & & & & & & \\
\hline \multirow{2}{*}{ 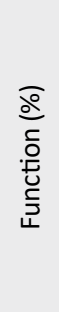 } & 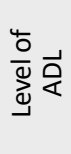 & 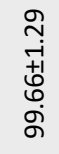 & $\begin{array}{l}0 \\
\stackrel{1}{1} \\
m \\
\infty \\
\infty\end{array}$ & $\begin{array}{l}0 \\
\stackrel{1}{1} \\
+1 \\
+1 \\
\sigma\end{array}$ & 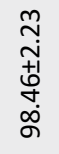 & 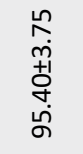 & $\sigma$ & N & §̊ & 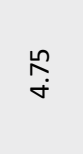 & & & $\begin{array}{l}\stackrel{*}{\circ} \\
\stackrel{8}{0} \\
0\end{array}$ & & & $\stackrel{*}{*}$ \\
\hline & $\frac{4}{0}$ 范 & $\begin{array}{l}\stackrel{n}{N} \\
i \\
+1 \\
m \\
m \\
g \\
\sigma\end{array}$ & $\begin{array}{l}\text { o } \\
\text { +1 } \\
\text { مे }\end{array}$ & 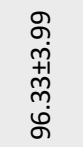 & $\begin{array}{l}\infty \\
\infty \\
+1 \\
\text { ळे }\end{array}$ & $\begin{array}{l}\infty \\
0 \\
m \\
m \\
m \\
\infty \\
\infty \\
\infty\end{array}$ & $\sigma$ & $\pi$ & $\stackrel{\infty}{0}$ & 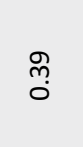 & & & & & & \\
\hline
\end{tabular}

ADL: Activities Of Daily Living; NG: Normal Foot Group; PG: Pronated Foot Group; HPG: Highly-Pronated Foot Group; SGA: Supinated Foot Group; HSG: Highly-Supinated Foot Group.

* Significant difference between groups: $\mathrm{P}<0.01$ in Bonferroni post hoc test

test was used to detect differences between groups related to the sex variable. $\mathrm{P}<0.05$ was considered significant.

\section{Results}

This study included 75 distance runners that were assigned into 5 groups using the FPI; normal foot group (NG) (15 distance runners), pronated foot group (PG) (15 distance runners), highly-pronated foot group (HPG) (15 distance runners), supinated foot group (SG) (15 distance runners) and highly-supinated foot group (HSG) (15 distance runners). The demographic characteristics of all participants are presented in Table 1. No significant differences were observed between the 5 groups regarding the demographic characteristics $(\mathrm{P}>0.05)$.

Comparisons results between all 5 foot posture groups for FAAM questionnaire, range of motions, plantar pressure percentage, and contact surface area are shown separately in Tables 2-5.

The scores of the FAAM questionnaire for all groups are summarized in Table 2. Significant differences were found in the ADL subscale and the level of ADL function between the groups. The runners in the normal foot group had a higher score in the ADL subscale than highly-supinated and highly-pronated foot groups. Also, the supinated foot group displayed a lower score in the ADL subscale compared to the normal, pronated, and supinated foot groups. The runners are asked to rate their current level of function. This item is ranged on a 4-point Likert-type scale as normal, nearly normal, abnormal, and severely abnormal. About $70.7 \%$ of the participants selected the normal status and $29.3 \%$ of the participants chose nearly normal status. The Chi-square test did not detect a significant difference among the groups regarding this item.

The gray squares indicate no-significant difference between the groups.

Ankle PF and MTP1 extension range of motions showed significant differences between the groups (Table 3). Compared with the foot pronated group, supinated, and highly-supinated foot groups, the highlypronated foot group had a significantly greater range of motion in the ankle PF. Also, the normal foot group showed more range of motion in the MTP1 extension compared with the pronated, highly-pronated, and supi- 
Table 3. Active range of motion results, including all group Mean $\pm S D, P$ value of 1 -way ANOVA, F index, P value, and $P$ value of Bonferroni post hoc test (group 1 vs. group 2$)^{*},(n=15)$

\begin{tabular}{|c|c|c|c|c|c|c|c|c|c|c|c|c|c|c|c|c|}
\hline & & & & lean \pm & & & & If & & & & S. HP & & & Is. NG & \\
\hline & & NG & PG & HPG & SG & HSG & คํ요 & Q & $\mathbf{P}$ & $\begin{array}{c}\mathbf{F} \\
\text { Index }\end{array}$ & PG & SG & HSG & PG & HPG & SG \\
\hline & 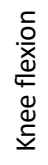 & 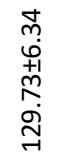 & 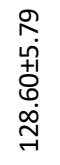 & 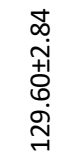 & 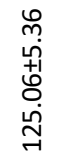 & 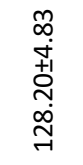 & $\sigma$ & $\stackrel{N}{N}$ & 움 & 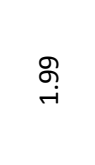 & & & & & & \\
\hline & 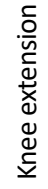 & 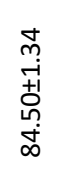 & 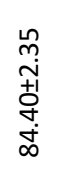 & 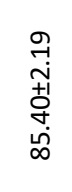 & 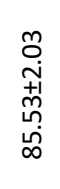 & 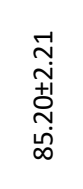 & $\nabla$ & N & ষ্ণ & นุ & & & & & & \\
\hline 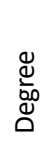 & 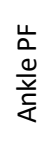 & 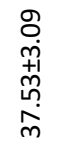 & 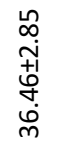 & 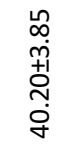 & 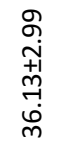 & 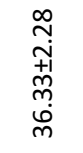 & $\nabla$ & N & రั & 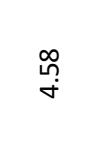 & $\begin{array}{l}\stackrel{*}{m} \\
\stackrel{0}{0} \\
0\end{array}$ & $\begin{array}{l}\stackrel{*}{\mathscr{L}} \\
\stackrel{\circ}{0}\end{array}$ & 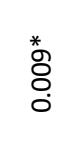 & & & \\
\hline & 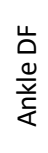 & 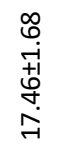 & 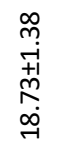 & $\begin{array}{l}\infty \\
0 \\
\text { p } \\
\text { +1 } \\
+ \\
+ \\
\infty \\
\rightarrow\end{array}$ & $\begin{array}{l}\stackrel{0}{m} \\
\underset{m}{+} \\
\underset{\infty}{\infty} \\
\rightarrow\end{array}$ & 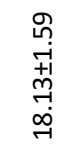 & $\nabla$ & ন & f̊ & $\begin{array}{l}\text { @ } \\
0 \\
0\end{array}$ & & & & & & \\
\hline & 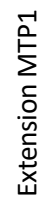 & 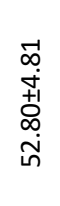 & $\begin{array}{l}\infty \\
\infty \\
\dot{p} \\
+1 \\
0 \\
\stackrel{+}{f} \\
\dot{f}\end{array}$ & 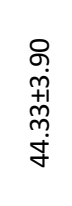 & $\begin{array}{l}0 \\
\infty \\
\dot{+} \\
+1 \\
\dot{+1} \\
\dot{\varphi} \\
\dot{y}\end{array}$ & 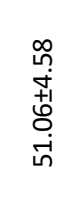 & $\nabla$ & N & 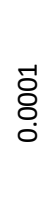 & 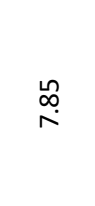 & & & 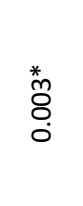 & $\begin{array}{l}\stackrel{J}{J}_{0}^{*} \\
\stackrel{0}{0}\end{array}$ & $\begin{array}{l}\stackrel{*}{\circ} \\
\stackrel{8}{0} \\
0\end{array}$ & $\stackrel{*}{\stackrel{*}{O}}$ \\
\hline
\end{tabular}

NG: Normal Foot Group; PG: Pronated Foot Group; HPG: Highly-Pronated Foot Group; SGA: Supinated Foot Group; HSG: Highly-Supinated Foot Group; PF: Plantar Flexion; DF: Dorsiflexion

* Significant difference (P value) between groups: $\mathrm{P}<0.05$ in Bonferroni post hoc test

nated foot groups. There was no significant difference between normal and highly-supinated foot groups in the extension range of motion MTP1 (Table 3).

The gray squares indicate no-significant difference between the groups.

Table 4 presents the findings for the percentage pressure on the foot. In this study, the subjects were instructed to distribute approximately equal weight on each lower extremity. For analysis, the pressure on each part was transformed to a percentage (from $0 \%$ to $100 \%$ ). In all groups, the percentage of pressure on the rearfoot was greater than the percentage of pressure on the forefoot (Table 4). Compared with the other groups, the highlysupinated foot group showed the highest percentage plantar pressure on the rearfoot, while the highly-pronated foot group showed the highest percentage plantar pressure on the forefoot (Table 4).
Table 5 presents the findings for the contact surface area. Compared with the normal, pronated, supinated, and highly-supinated foot groups, the highly-pronated foot group demonstrated the largest contact surface area for the rearfoot, and compared with the normal, pronated, highlypronated and supinated foot groups and the forefoot part, the normal foot group had greater contact area than the pronated and highly-supinated foot groups (Table 5).

The gray squares indicate no-significant difference between the groups.

\section{Discussion}

The present study was intended to compare a range of motions, foot function, distribution of plantar pressure, and plantar contact area between the distance runners with normal, pronated, highly-pronated, supinated, and highlysupinated foot postures. Our data showed that the ankle and 
Table 4. Plantar pressure (\%) results, including all group Mean \pm SD, P value of 1-way ANOVA, F index, and P value of Bonferroni post hoc test (group 1 vs. group 2$) *,(n=15)$

\begin{tabular}{|c|c|c|c|c|c|c|c|c|c|c|c|c|c|}
\hline \multirow[b]{2}{*}{$\begin{array}{c}\text { Groups Vari- } \\
\text { ables }\end{array}$} & \multicolumn{5}{|c|}{ Mean $\pm S D$} & \multicolumn{2}{|c|}{ df } & \multirow[b]{2}{*}{$\mathbf{P}$} & \multirow[b]{2}{*}{$\begin{array}{c}\mathbf{F} \\
\text { Index }\end{array}$} & \multicolumn{2}{|c|}{ HPG vs. } & \multicolumn{2}{|c|}{ HSG vs. } \\
\hline & NG & PG & HPG & SG & HSG & 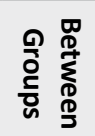 & 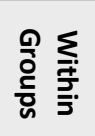 & & & NG & PG & HPG & SG \\
\hline 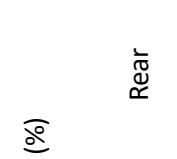 & 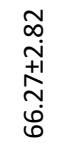 & 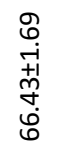 & $\begin{array}{l}\text { 엄 } \\
\text { m } \\
\text { +1 } \\
0 \\
\text { ம் }\end{array}$ & \begin{tabular}{l}
$\varphi$ \\
$\ddot{x}$ \\
+1 \\
+1 \\
\multirow{2}{*}{}
\end{tabular} & 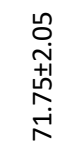 & $\theta$ & $\stackrel{N}{A}$ & ठ্ & $\stackrel{\text { \& }}{\underset{\sim}{+}}$ & $\begin{array}{l}\stackrel{*}{-1} \\
\stackrel{0}{0} \\
\stackrel{0}{0}\end{array}$ & 苂 & $\stackrel{*}{*}$ & $\begin{array}{l}\stackrel{*}{-} \\
\delta \\
\delta\end{array}$ \\
\hline 훈 & $\begin{array}{l}\stackrel{\sim}{\infty} \\
\underset{N}{+} \\
\underset{N}{N} \\
m \\
m\end{array}$ & 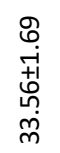 & 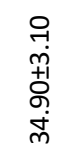 & 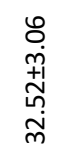 & 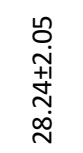 & $\nabla$ & N & ठ্ & $\underset{\stackrel{n}{\sim}}{\stackrel{\sim}{\sim}}$ & 范 & 苂 & $\begin{array}{l}\stackrel{*}{\circ} \\
8 \\
\delta\end{array}$ & $\begin{array}{l}\stackrel{*}{\circ} \\
\stackrel{\circ}{8} \\
0\end{array}$ \\
\hline
\end{tabular}

$J M R$

NG: Normal Foot Group; PG: Pronated Foot Group; HPG: Highly-Pronated Foot Group; SGA: Supinated Foot Group; HSG: Highly-Supinated Foot Group

* Significant difference ( $\mathrm{P}$ value) between groups: $\mathrm{P}<0.05$ in Bonferroni post hoc test

foot range of motions, function, distribution of plantar pressure, and contact surface area could be affected by the type of foot posture. This is the first study that was conducted on 5 foot postures (normal, pronated, highly-pronated, supinated, and highly-supinated foot postures). All foot postures in the present study were assigned using the FPI.

The findings of the FAAM questionnaire indicated that the scores of activities daily living subscale in the highlysupinated and highly-pronated foot groups were lower compared with that of the normal group. Among the groups, the normal foot group showed the highest score in both of the subscales. The supinated and pronated foot groups did not show significant differences in total scores of both subscales compared with the normal feet group. Although all the subjects in our study reported pain intensity lower than 3 according to the visual analog scale, lower scores in the FAAM scales in the highly supinated foot group can indicate that level of performance of foot and ankle can be affected by abnormal foot posture.

Table 5. Plantar contact surface area $\left(\mathrm{cm}^{2}\right)$ results, including all group Mean $\pm S D, P$ value of 1-way ANOVA, F index, P value, and $\mathrm{P}$ value of Bonferroni post hoc test (group 1 vs. group 2)*, (n=15)

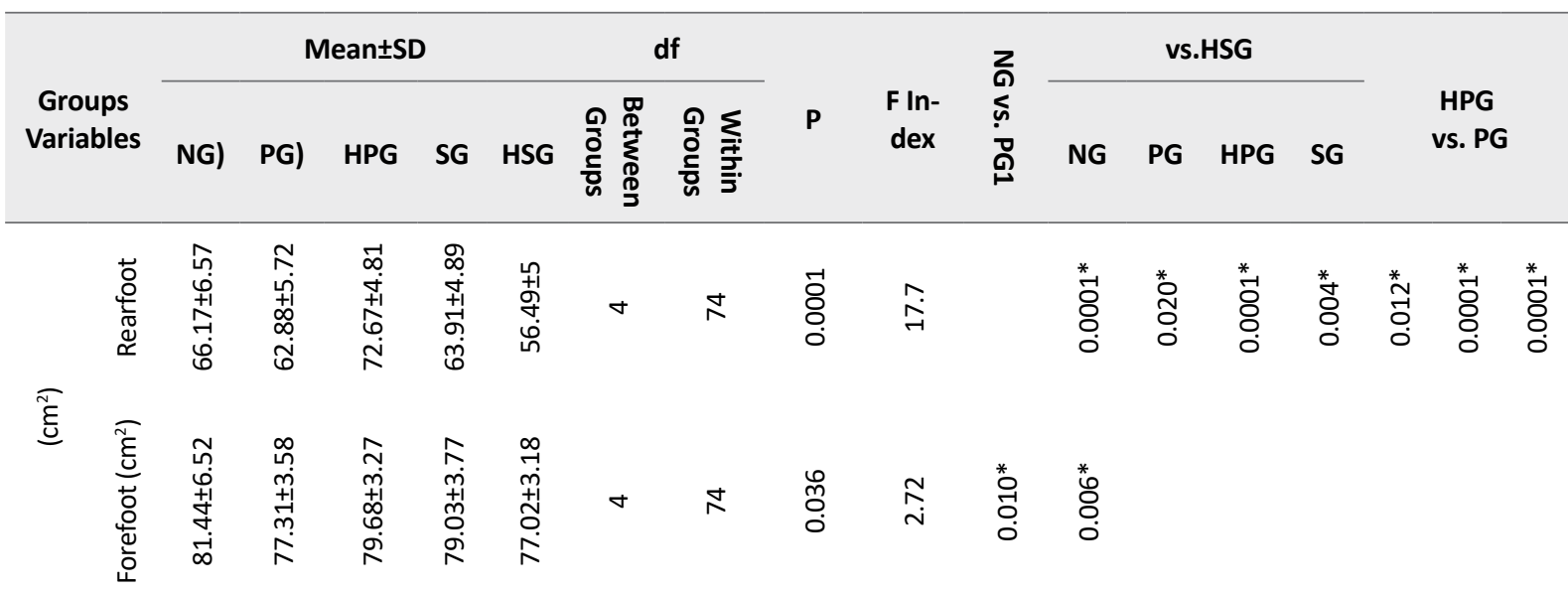

NG: Normal Foot Group; PG: Pronated Foot Group; HPG: Highly-Pronated Foot Group; SGA: Supinated Foot Group; HSG: Highly-Supinated Foot Group

* Significant difference ( $\mathrm{P}$ value) between groups: $\mathrm{P}<0.05$ in Bonferroni post hoc test 
Another finding in our study was the effect of foot posture on the range of motions. Some studies have reported that the foot posture has affected the range of motion of the lower extremity $[6,10,13,17]$. Significant differences were also found in the ankle plantar flexion and extension of MTP1 between the groups. In the present study, the athletes with highly-pronated foot posture had greater plantarflexion compared with the pronated, supinated, and highly-pronated foot groups. This finding is in line with other studies that have compared plantar flexion between foot postures. Hunt AE et al. compared normal and pes planus foot groups and found that the pes planus group displayed more plantar flexion of the rearfoot at $21 \%$ of stance phase than the normal feet group [14]. Levinger et al. used the X-ray to categorize foot postures; their results showed that compared with the normal group, the pes planus group had more forefoot plantar flexion [24].

Our results also indicated that the MTP1 extension in the normal foot group was more than the other groups and the highly-pronated foot group had the smallest MTP1 extension. It is also similar to the finding of Smita Rao et al. that reported low arch foot group displayed lower flexibility in MTP1 than the other groups [15]. This finding is in agreement with the theory that pes planus foot posture could change the alignment of the first metatarsal bone and decrease big toe extension mobility [38]. Considering the above findings, type of foot posture could affect the foot mobility and individuals with low or high foot arch may be more susceptible to musculoskeletal foot syndromes such as plantar fasciitis and the first MTP osteoarthritis than subjects with normal feet posture.

The present study also showed significant differences between the groups in plantar pressure percentage. All subjects in this study showed a greater pressure percentage on the rearfoot than on the forefoot. It is also similar to the finding of Tuna et al. [39]. They reported that in healthy people, approximately $2 / 3$ of total weight was applied to the rearfoot in the standing position, but the type of foot posture was not defined in their study. In our study, the foot plantar was divided into two parts. One part was named the rearfoot that included medial heel, lateral heel, and midfoot, and the other part was named the forefoot that included the metatarsals and the phalanges. Compared with the other groups in the present study, the highly-supinated foot group demonstrated the highest plantar pressure percentage on the rear foot, while the highly-pronated foot group displayed the highest plantar pressure percentage on the forefoot during the standing position.

In line with our study, Joshua Burns et al. found that the pressure on the rearfoot in the idiopathic cavus group was more than the normal foot group [19]. Also, Jin Tae Han et al. compared the distribution of foot pressure between normal and pes planus feet postures [40]. They demonstrated that in the big toe, small toe, the second, third metatarsal, the plantar pressure of the pes planus group was higher than the normal group.

In addition to the above variables, when the contact surface area was compared between the groups, statistically significant differences were observed. In the rearfoot area, the highly-pronated foot group had the greatest contact surface and the highly-supinated foot group had the smallest contact surface. According to the study by A K. Buldt et al., the pes planus group showed a greater contact area in the midfoot than the normal and pes cavus groups [21]. In the present study, the midfoot was considered a part of the rearfoot. It may be a possible reason that the highly-pronated foot group showed greater contact area in the rearfoot than the other groups. In the forefoot part, the normal feet group had a greater contact area than the pronated and highly-supinated feet groups. One of the limitations in this study was that in our study, compared to other studies, the foot was divided into only two parts, and due to the existence of overlapping between different sections of each part, the details of differences may have been missed. So, any interpretation of these results about foot pressure and contact area in this study should be considered with caution.

\section{Conclusion}

Differences in ankle plantar flexion, MTP1 extension, foot function, distribution of the plantar pressure, and the plantar contact area between distance runners with different foot postures classified according to FPI were detected. The normal foot group demonstrated more scores in the FAAM questionnaire than the others. The athletes with highly-pronated foot demonstrated greater ankle plantarflexion, greater plantar pressure percentage on the forefoot, and greater contact area in the rearfoot during static standing. Increased plantar pressure percentage on the rearfoot was also found in the highly-supinated foot group. Based on the study results, the findings in the pronated and supinated foot groups were approximately similar to the normal foot group. Further research with separating of the foot into more parts is required to explore the more differences between 5 foot postures according to the FPI. 


\section{Ethical Considerations}

Compliance with ethical guidelines

All study procedures were performed after the study was approved by the Scientific Board and Ethics Committee of the School of Rehabilitation, Tehran University of Medical Science (Code: IR-TUMS-VCRREC.1398.994; 2020-03-01)

\section{Funding}

The present paper was extracted from the Master's thesis of the first author, Department of Physiotherapy, School of Rehabilitation, Tehran University of Medical Sciences.

\section{Authors contributions}

Data collection, writing the original draft: Navid Keivanfar, Saman Salehi; Writing the original drafts, Approving the final version of the manuscript: All authors.

\section{Conflict of interest}

The authors declared no conflict of interest.

\section{Acknowledgements}

The authors would like to thank all of the distance runners that participated in this study.

\section{References}

[1] Bahr R, Krosshaug T. Understanding injury mechanisms: A key component of preventing injuries in sport. British Journal of Sports Medicine. 2005; 39(6):324-9. [DOI:10.1136/ bjsm.2005.018341] [PMID] [PMCID]

[2] Carson DW, Myer GD, Hewett TE, Heidt Jr RS, Ford KR. Increased plantar force and impulse in American football players with high arch compared to normal arch. The Foot. 2012; 22(4):310-4. [DOI:10.1016/j.foot.2012.09.002] [PMID] [PMCID]

[3] Cowan DN, Jones BH, Robinson JR. Foot morphologic characteristics and risk of exercise-related injury. Archives of Family Medicine. 1993; 2(7):773-7. [DOI:10.1001/archfami.2.7.773] [PMID]

[4] Tong JWK, Kong PW. Association between foot type and lower extremity injuries: Systematic literature review with metaanalysis. Journal of Orthopaedic \& Sports Physical Therapy. 2013; 43(10):700-14. [DOI:10.2519/jospt.2013.4225] [PMID]

[5] Neal BS, Griffiths IB, Dowling GJ, Murley GS, Munteanu SE, Smith MMF, et al. Foot posture as a risk factor for lower limb overuse injury: A systematic review and meta-analysis. Jour- nal of Foot and Ankle Research. 2014; 7(1):55. [DOI:10.1186/ s13047-014-0055-4] [PMID] [PMCID]

[6] Kaufman KR, Brodine SK, Shaffer RA, Johnson CW, Cullison TR. The effect of foot structure and range of motion on musculoskeletal overuse injuries. The American Journal of Sports Medicine. 1999; 27(5):585-93. [DOI:10.1177/036354659 90270050701] [PMID]

[7] Dahle LK, Mueller MJ, Delitto A, Diamond JE. Visual assessment of foot type and relationship of foot type to lower ex tremity injury. Journal of Orthopaedic \& Sports Physical Therapy. 1991; 14(2):70-4. [DOI:10.2519/jospt.1991.14.2.70] [PMID]

[8] Williams Iii DS, McClay IS, Hamill J. Arch structure and injury patterns in runners. Clinical Biomechanics. 2001; 16(4):341-7. [DOI:10.1016/S0268-0033(01)00005-5] [PMID]

[9] Barnes A, Wheat J, Milner C. Association between foot type and tibial stress injuries: A systematic review. British Journal of Sports Medicine. 2008; 42(2):93-8. [DOI:10.1136/ bjsm.2007.036533]

[10] Powell DW, Andrews S, Stickley C, Williams DB. Highcompared to low-arched athletes exhibit smaller knee abduction moments in walking and running. Human Movement Science. 2016; 50:47-53. [DOI:10.1016/j.humov.2016.10.006]

[11] Powell DW, Hanson NJ, Long B, Williams III DSB. Frontal plane landing mechanics in high-arched compared with lowarched female athletes. Clinical Journal of Sport Medicine. 2012 22(5):430-5. [DOI:10.1097/JSM.0b013e318257d5a1] [PMID]

[12] Cobb SC, Tis LL, Johnson JT, Geil MD, McCarty FA. The effect of low-mobile foot posture on multi-segment medial foot model gait kinematics. Gait \& Posture. 2009; 30(3):334-9. [DOI:10.1016/j.gaitpost.2009.06.005] [PMID]

[13] Buldt AK, Levinger P, Murley GS, Menz HB, Nester CJ Landorf KB. Foot posture is associated with kinematics of the foot during gait: A comparison of normal, planus and cavus feet. Gait \& Posture. 2015; 42(1):42-8. [DOI:10.1016/j.gaitpost.2015.03.004] [PMID]

[14] Hunt AE, Smith RM. Mechanics and control of the flat versus normal foot during the stance phase of walking. Clinical Biomechanics. 2004; 19(4):391-7. [DOI:10.1016/j.clinbiomech.2003.12.010] [PMID]

[15] Rao S, Song J, Kraszewski A, Backus S, Ellis SJ, Deland JT, et al. The effect of foot structure on 1st metatarsophalangeal joint flexibility and hallucal loading. Gait \& Posture. 2011;34(1):131 7. [DOI:10.1016/j.gaitpost.2011.02.028] [PMID] [PMCID]

[16] Hamill J, Bates BT, Knutzen KM, Kirkpatrick GM. Relationship between selected static an dynamic lower extremity measures. Clinical Biomechanics. 1989; 4(4):217-25. [DOI:10.1016/0268-0033(89)90006-5]

[17] Buldt AK, Murley GS, Butterworth P, Levinger P, Menz $\mathrm{HB}$, Landorf KB. The relationship between foot posture and lower limb kinematics during walking: A systematic review. Gait \& Posture. 2013; 38(3):363-72. [DOI:10.1016/j.gaitpost.2013.01.010] [PMID]

[18] Jonely H, Brismée J-M, Sizer Jr PS, James CR. Relationships between clinical measures of static foot posture and plantar pressure during static standing and walking. Clinical Biomechanics. 2011; 26(8):873-9. [DOI:10.1016/j.clinbiomech.2011.04.008] [PMID] 
[19] Burns J, Crosbie J, Hunt A, Ouvrier R. The effect of pes cavus on foot pain and plantar pressure. Clinical Biomechanics. 2005, 20(9):877-82. [DOI:10.1016/j.clinbiomech.2005.03.006] [PMID]

[20] Fernández-Seguín LM, Mancha JAD, Rodríguez RS, Martínez EE, Martín BG, Ortega JR. Comparison of plantar pressures and contact area between normal and cavus foot. Gait \& Posture. 2014; 39(2):789-92. [DOI:10.1016/j.gaitpost.2013.10.018] [PMID]

[21] Buldt AK, Forghany S, Landorf KB, Levinger P, Murley GS, Menz HB. Foot posture is associated with plantar pressure during gait: A comparison of normal, planus and cavus feet. Gait \& Posture. 2018; 62:235-40. [DOI:10.1016/j.gaitpost.2018.03.005] [PMID]

[22] Buldt AK, Allan JJ, Landorf KB, Menz HB. The relationship between foot posture and plantar pressure during walking in adults: A systematic review. Gait \& Posture. 2018; 62:56-67. [DOI:10.1016/j.gaitpost.2018.02.026] [PMID]

[23] McLaughlin P, Vaughan B, Shanahan J, Martin J, Linger G. Inexperienced examiners and the foot posture index: A reliability study. Manual Therapy. 2016; 26:238-40. [DOI:10.1016/j. math.2016.06.009] [PMID]

[24] Levinger P, Murley GS, Barton CJ, Cotchett MP, McSweeney SR, Menz HB. A comparison of foot kinematics in people with normal-and flat-arched feet using the Oxford Foot Model. Gait \& Posture. 2010; 32(4):519-23. [DOI:10.1016/j. gaitpost.2010.07.013] [PMID]

[25] Cavanagh PR, Rodgers MM. The arch index: A useful measure from footprints. Journal of Biomechanics. 1987; 20(5):547-51. [DOI:10.1016/0021-9290(87)90255-7]

[26] Redmond AC, Crane YZ, Menz HB. Normative values for the foot posture index. Journal of Foot and Ankle Research. 2008; 1(1):6. [DOI:10.1186/1757-1146-1-6] [PMID] [PMCID]

[27] Jarvis HL, Nester CJ, Bowden PD, Jones RK. Challenging the foundations of the clinical model of foot function: Further evidence that the root model assessments fail to appropriately classify foot function. Journal of Foot and Ankle Research. 2017; 10:7. [DOI:10.1186/s13047-017-0189-2] [PMID] [PMCID]

[28] McPoil T, Cornwall MW. Relationship between neutral subtalar joint position and pattern of rearfoot motion during walking. Foot \& Ankle International. 1994; 15(3):141-5. [DOI:1 0.1177/107110079401500309] [PMID]

[29] Redmond AC, Crosbie J, Ouvrier RA. Development and validation of a novel rating system for scoring standing foot posture: The Foot Posture Index. Clinical Biomechanics. 2006; 21(1):89-98. [DOI:10.1016/j.clinbiomech.2005.08.002] [PMID]

[30] Morrison SC, Ferrari J. Inter-rater reliability of the Foot Posture Index (FPI-6) in the assessment of the paediatric foot. Journal of Foot and Ankle Research. 2009; 2:26. [DOI:10.1186/1757-1146-2-26] [PMID] [PMCID]

[31] Aquino MRC, Avelar BS, Silva PL, Ocarino JM, Resende RA. Reliability of Foot Posture Index individual and total scores for adults and older adults. Musculoskeletal Science and Practice. 2018; 36:92-5. [DOI:10.1016/j.msksp.2018.02.002] [PMID]

[32] Unver B, Erdem EU, Akbas E. Effects of short-foot exercises on foot posture, pain, disability, and plantar pressure in Pes Planus. Journal of Sport Rehabilitation. 2019; 29(4):436-40. [DOI:10.1123/jsr.2018-0363] [PMID]
[33] Munteanu SE, Zammit GV, Menz HB. Factors associated with foot pain severity and foot-related disability in individuals with first metatarsophalangeal joint OA. Rheumatology. 2012; 51(1):176-83. [DOI:10.1093/rheumatology/ker344] [PMID]

[34] Mazaheri M, Salavati M, Negahban H, Sohani SM, Taghizadeh F, Feizi A, et al. Reliability and validity of the Persian version of Foot and Ankle Ability Measure (FAAM) to measure functional limitations in patients with foot and ankle disorders. Osteoarthritis and Cartilage. 2010; 18(6):755-9. [DOI:10.1016/j.joca.2010.03.006] [PMID]

[35] Martin RL, Irrgang JJ, Burdett RG, Conti SF, Swearingen JMV. Evidence of validity for the Foot and Ankle Ability Measure (FAAM). Foot \& Ankle International. 2005; 26(11):968-83. [DOI:10.1177/107110070502601113] [PMID]

[36] Norkin CC, White DJ. Measurement of joint motion: A guide to goniometry. $5^{\text {th }}$ ed. Philadelphia: FA Davis; 2016. https://www.amazon.com/Measurement-Joint-MotionGuide-Goniometry/dp/080364566X

[37] Birtane $M$, Tuna $H$. The evaluation of plantar pressure distribution in obese and non-obese adults. Clinical Biomechanics. 2004; 19(10):1055-9. [DOI:10.1016/j.clinbiomech.2004.07.008] [PMID]

[38] Glasoe WM, Nuckley DJ, Ludewig PM. Hallux valgus and the first metatarsal arch segment: A theoretical biomechanical perspective. Physical Therapy. 2010; 90(1):110-20. [DOI:10.2522/ptj.20080298] [PMID]

[39] Tuna H, Yildiz M, Celtik C, Kokino S. Static and dynamic plantar pressure measurements in adolescents. Acta Orthopaedica et Traumatologica Turcica. 2004; 38(3):200-5. [PMID]

[40] Han JT, Koo HM, Jung JM, Kim YJ, Lee JH. Differences in plantar foot pressure and COP between flat and normal feet during walking. Journal of Physical Therapy Science. 2011; 23(4):683-5. [DOI:10.1589/jpts.23.683] 